\title{
BMJ Open Efficacy and safety of remdesivir in COVID-19 caused by SARS-CoV-2: a systematic review and meta-analysis
}

\author{
Surjit Singh (D) , ${ }^{1}$ Daisy Khera, ${ }^{2}$ Ankita Chugh, ${ }^{3}$ Pushpinder Singh Khera, ${ }^{4}$ \\ Vinay Kumar Chugh ${ }^{3}$
}

To cite: Singh S, Khera D, Chugh A, et al. Efficacy and safety of remdesivir in COVID- 19 caused by SARSCoV-2: a systematic review and meta-analysis. BMJ Open 2021;11:e048416. doi:10.1136/ bmjopen-2020-048416

- Prepublication history and additional supplemental material for this paper are available online. To view these files, please visit the journal online (http://dx.doi.org/10.1136/ bmjopen-2020-048416).

SS, DK and AC contributed equally.

Received 24 December 2020 Accepted 14 May 2021

Check for updates

(c) Author(s) (or their employer(s)) 2021. Re-use permitted under CC BY-NC. No commercial re-use. See rights and permissions. Published by BMJ.

'Department of Pharmacology, All India Institute of Medical Sciences, New Delhi, India ${ }^{2}$ Department of Pediatrics, All India Institute of Medical Sciences, New Delhi, India ${ }^{3}$ Department of Dentistry, All India Institute of Medical Sciences, New Delhi, India ${ }^{4}$ Department of Diagnostic and Interventional Radiology, All India Institute of Medical Sciences, New Delhi, India

Correspondence to Dr Ankita Chugh; ankitamody@gmail.com

\section{ABSTRACT}

Objectives Evaluation of remdesivir, an RNA polymerase inhibitor, for effectiveness in adults with COVID-19.

Data sources Electronic search for eligible articles of PubMed, Cochrane Central and clinicaltrials.gov was performed on 20 September 2020.

Participants and study eligibility criteria Only randomised controlled trials (RCTs) evaluating efficacy of remdesivir in COVID-19 were included for meta-analysis. Interventions Remdesivir was compared with standard of care.

Primary and secondary outcomes Primary outcome was mortality and secondary outcomes were time to clinical improvement and safety outcomes like serious adverse events, respiratory failure.

Study appraisal and synthesis methods Data synthesis was done with Cochrane review manager 5 (RevMan) V.5.3. Cochrane risk of bias V.2.0 tool was used for methodological quality assessment. The GRADE pro GDT was applied for overall quality of evidence.

Results 52 RCTs were screened and 4 studies were included in analysis, with total of 7324 patients. No mortality benefit was observed with remdesivir versus control group ( $\mathrm{OR}=0.92$ ( $95 \% \mathrm{Cl} 0.79$ to 1.07$), \mathrm{p}=0.30$, moderate quality evidence). Significantly higher rates of clinical improvement $(\mathrm{OR}=1.52(95 \% \mathrm{Cl} 1.24$ to 1.87), $\mathrm{p}<0.0001$, low quality) and faster time to clinical improvement ( $\mathrm{HR}=1.28$ (95\% Cl 1.12 to 1.46), $p=0.0002$, very low quality) was observed with remdesivir versus control group. Significant decrease was found in the risk of serious adverse events ( $\mathrm{RR}=0.75$ ( $95 \% \mathrm{Cl} 0.62$ to 0.90$)$, $\mathrm{p}=0.0003$, low quality); however, no difference was found in the risk of respiratory failure (RR=0.85 $(95 \% \mathrm{Cl} 0.41$ to 1.77 ), $p=0.67$, very low quality evidence) with remdesivir. Conclusions As per the evidence from current review, remdesivir has shown no mortality benefit (moderate quality evidence) in the treatment of COVID-19. From a cost-benefit perspective, it is our personal opinion that it should not be recommended for use, especially in low and lower middle income countries.

Trial registration number PROSPERO registration number: CRD42020189517.

\section{INTRODUCTION}

COVID-19 has created a pandemic all over the world. $^{12}$ The global pandemic of SARS-CoV-2 infections has affected more than 141 million

\section{Strengths and limitations of this study}

- Four randomised controlled trials (RCTs) were included in our analysis with total sample size of 7324 patients.

- Risk of bias (ROB) of RCTs was done using Cochrane ROB-2 scale.

- ROB-2 showed low ROB for WHO Solidarity trial and Wang et al and high ROB for Beigel et al and Spinner et al

- GRADE was applied and overall evidence suggested no mortality benefit with remdesivir (moderate quality evidence).

- Cost-benefit analysis revealed higher cost with no mortality benefit.

people worldwide and has been the cause of 3.026 million deaths globally by 18 April 2021 as per COVID-19 statistics data. Around 120 million people have recovered and as the trend suggests most of them stay asymptomatic and few of them develop pneumonialike symptoms that does not require oxygen support. ${ }^{3}$ A very small percentage get critical to the limit of hypoxia, acute respiratory distress syndrome and multiorgan failure. Among these critical patients who are being put on mechanical ventilation, half of them die.

The search for an effective therapy or preventive modality has become the utmost need of the hour. There are few proposed and approved drugs with some antiviral action and they are under investigation simultaneously across the globe. But as yet no proven effective therapy for SARS-CoV-2 has been accepted widely. Among the few promising therapies available remdesivir, a viral RNA polymerase inhibitor has been recommended by US Food and Drug Administration (FDA) as a drug for compassionate use for treatment of patients with COVID-19. Remdesivir, a nucleoside analogue prodrug, has shown inhibitory effects on SARS-CoV-2, 


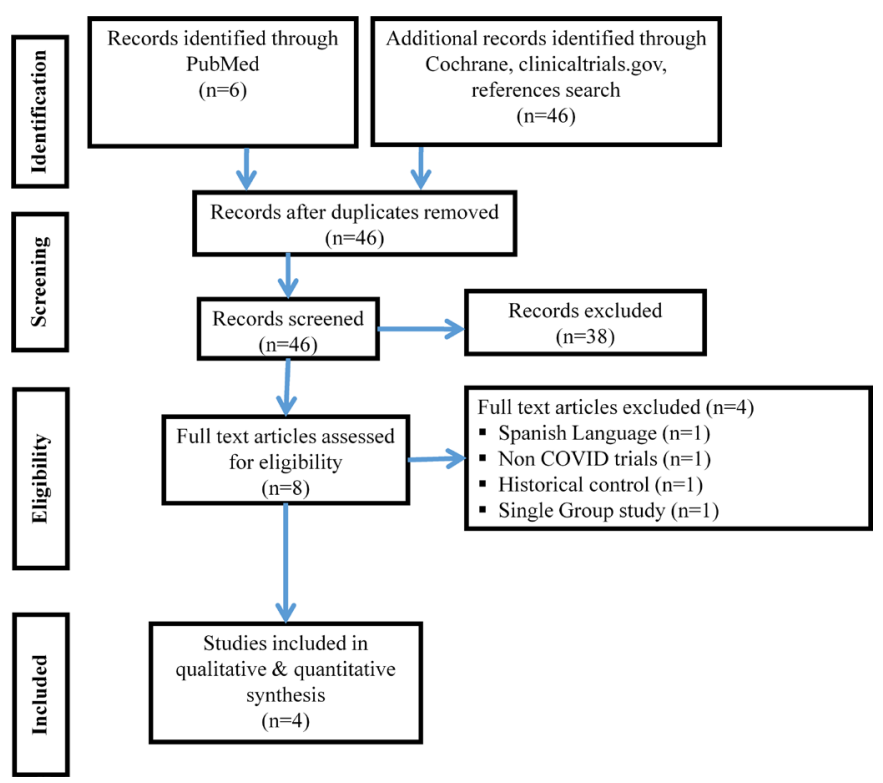

Figure 1 PRISMA flow chart depicting study selection process.

both in vitro and in animal models. However, even for the above-mentioned studies, contrasting results have been reported in different nations like China and USA. ${ }^{3}$ Varied study designs, ${ }^{45}$ genetic reasons and different treatment regimens ( 5 or 10 days) have been attributed for this difference.

Only two randomised controlled trials (RCT) have shown efficacy of remdesivir in patients with COVID19. Many RCTs are undergoing to assess the benefit-risk ratio of remdesivir. Current review was planned to assess the mortality and clinical benefit in addition to safety of remdesivir in the treatment of COVID-19 caused by SARS-CoV-2.

\section{METHODS}

\section{Protocol and registration}

Review was done following the "PRISMA (Preferred Reporting Items for Systematic Reviews and MetaAnalyses") statement. "PROSPERO (International Prospective Register of Systematic Reviews) database" registration was done with study number as CRD42020189517.

\section{Inclusion criteria}

Exclusively RCTs evaluating role of remdesivir compared with standard care in COVID-19 were included. Observational studies, review articles, case reports or case series were excluded.

\section{Search and selection of studies}

Electronic literature search was performed in PubMed, Cochrane Central Register of Controlled Trials, in addition to clinicaltrials.gov on 20 September 2020, to identify the relevant published articles. Additional search was done in November 2020 for results of completed trials. Bibliographic search of published articles were also done manually to identify more studies. Only English language studies published were included. Search was performed using medical headings like 'SARS-CoV-2', 'COVID-19', 'Remdesivir', 'COVID-19', 'novel coronavirus'. RCT restriction was applied. PubMed search strategy is given in online supplemental file 1 ).

After removal of duplicate articles, two independent authors reviewed the studies for inclusion in review.

\section{Data extraction}

Study design, remdesivir doses and regimens, total subjects along with their characteristics, efficacy and safety outcomes were extracted and filled on a prestructured form.

\section{Study objectives}

The primary objective of review was assessment of mortality (defined as deaths in each group). The secondary outcomes were clinical improvement and virological cure. In addition, serious adverse events (AEs) and other safety parameters were assessed. Cost-benefit analysis was also performed for remdesivir.

\section{Quality assessment}

Two authors independently (DK and AC) performed risk of bias (ROB) of RCTs using Cochrane Collaboration ROB-2. ${ }^{6}$ Overall assessment was recorded as high, low and some concerns. Synthesis of ROB plots was done using online software Robvis (visualisation tool). ${ }^{7}$

For publication bias assessment, funnel plot asymmetry was not assessed as studies were less than five. However, Egger's regression test was applied.

\section{Data synthesis and summary measures}

Mortality and other outcome data were presented as OR or HR with $95 \%$ CIs. Synthesis of data was done using "Review Manager 5 (RevMan) Version 5.3" (Copenhagen: The Nordic Cochrane Centre, The Cochrane Collaboration, 2014). ${ }^{8}$ The heterogeneity among RCTs included in review was judged with $\mathrm{I}^{2} .{ }^{10}$ The results of both fixed and random effect model were assessed for interpretation..$^{911}$

\section{Quality of evidence-GRADE Pro GDT}

GRADE pro GDT (guideline development tool) software (https://gradeproorg/.) was applied for assessment of overall quality of evidence. ${ }^{12}$ Optimal information size or sample size for either group was computed to be 1213 patients. Overall GRADE assessment was classified as high, moderate, low or very low. ${ }^{12}$

\section{Patient and public involvement}

Patients or the public were not involved in the design, or conduct, or reporting, or dissemination plans of our research.

\section{RESULTS}

\section{Study PRISMA flow diagram}

The RCTs included in review are depicted in PRISMA flow chart (figure 1). Out of total 52 records screened, 
Table 1 Characteristics of clinical studies evaluating remdesivir for treatment of COVID-19

\begin{tabular}{|c|c|c|c|c|c|}
\hline $\begin{array}{l}\text { Author, year } \\
\text { (study design) }\end{array}$ & $\begin{array}{l}\text { Institution/country of } \\
\text { study conduct }\end{array}$ & $\begin{array}{l}\text { Study interventions } \\
\text { (N)/regimen }\end{array}$ & $\begin{array}{l}\text { Study control } \\
(\mathrm{N}) / \text { regimen }\end{array}$ & $\begin{array}{l}\text { Study population } \\
\text { characteristics }\end{array}$ & Study outcomes \\
\hline $\begin{array}{l}\text { Beigel et al } 2020 \\
\text { (randomised } \\
\text { controlled trial) }\end{array}$ & Multicentre trial & $\begin{array}{l}\text { Remdesivir (538); } \\
200 \mathrm{mg} \text { on day } 1 \\
\text { followed by } 100 \mathrm{mg} \\
\text { on days } 2-10 \text { in single } \\
\text { daily infusions }\end{array}$ & Placebo (521) & $\begin{array}{l}\text { Hospitalised adults } \\
\text { patients with COVID-19 } \\
\text { with evidence of } \\
\text { lower respiratory tract } \\
\text { involvement. }\end{array}$ & $\begin{array}{l}\text { Time to recovery: Patients in the } \\
\text { remdesivir group had a shorter time to } \\
\text { recovery than patients in the placebo } \\
\text { group (median, } 11 \text { days, as compared } \\
\text { with } 15 \text { days; rate ratio for recovery, } \\
1.32 ; 95 \% \mathrm{Cl}(\mathrm{Cl}), 1.12 \text { to } 1.55 ; \\
\text { p<0.001 } \\
\text { Mortality: Kaplan-Meier estimates of } \\
\text { mortality by } 14 \text { days were } 7.1 \% \text { with } \\
\text { remdesivir and } 11.9 \% \text { with placebo } \\
\text { (HR for death, } 0.70 ; 95 \% \mathrm{Cl}, 0.47 \text { to } \\
1.04 \text { ) }\end{array}$ \\
\hline $\begin{array}{l}\text { Spinner et al } \\
\text { (randomised } \\
\text { controlled trial) }\end{array}$ & Multicentre trial & $\begin{array}{l}\text { Remdesivir - } 10 \text { days } \\
(n=197) \text {, } \\
\text { Remdesivir - } 5 \text { days } \\
(n=199)\end{array}$ & $\begin{array}{l}\text { Standard care } \\
(n=200)\end{array}$ & $\begin{array}{l}\text { Confirmed SARS-CoV-2 } \\
\text { infection and moderate } \\
\text { COVID-19 pneumonia } \\
\text { (pulmonary infiltrates and } \\
\text { room-air oxygen saturation } \\
>94 \% \text { ) }\end{array}$ & $\begin{array}{l}\text { Day } 28 \\
\text { Mortality rate } n(\%) \text { - remdesivir } 10 \\
\text { day=3 (2); remdesivir } 5 \text { days }=2(1), \\
\text { standard }=4(2) \\
\text { Clinical Improvement } n(\%) \text { - remdesivir } \\
10 \text { day }=174((90), \text { remdesivir } \\
5 \text { day }=171(90), \text { Standard }=166(83)\end{array}$ \\
\hline $\begin{array}{l}\text { Wang et al } 2020 \\
\text { (randomised } \\
\text { controlled trial) }\end{array}$ & $\begin{array}{l}\text { Department of } \\
\text { Pulmonary and Critical } \\
\text { Care Medicine, China- } \\
\text { Japan Friendship } \\
\text { Hospital, Beijing, China }\end{array}$ & $\begin{array}{l}\text { Remdesivir (158); } \\
\text { at least } 1 \text { dose after } \\
\text { entering ICU; } 200 \mathrm{mg} \\
\text { on day } 1 \text { followed } \\
\text { by } 100 \mathrm{mg} \text { on days } \\
2-10 \text { in single daily } \\
\text { infusions }\end{array}$ & Placebo (79) & $\begin{array}{l}\text { Hospitalised adults } \\
\text { patients with COVID-19 } \\
\text { symptom onset to } \\
\text { enrolment interval of } \leq 12 \\
\text { days, oxygen saturation } \\
\leq 94 \% \text { on room air or a } \\
\text { ratio of arterial oxygen } \\
\text { partial pressure to } \\
\text { fractional inspired oxygen } \\
\text { of } 300 \mathrm{~mm} \text { Hg or less, and } \\
\text { radiologically confirmed } \\
\text { pneumonia }\end{array}$ & $\begin{array}{l}\text { Time to clinical improvement } \\
\text { within } 28 \text { days after randomisation: } \\
\text { Remdesivir use was not associated } \\
\text { with a difference in time to clinical } \\
\text { improvement (HR } 1.23 \text { ( } 95 \% \mathrm{Cl} 0.87 \\
\text { to } 1.75) \text { ). Although not statistically } \\
\text { significant, patients receiving } \\
\text { remdesivir had a numerically faster } \\
\text { time to clinical improvement than } \\
\text { those receiving placebo among } \\
\text { patients with symptom duration of } 10 \\
\text { days or less (HR } 1.52 \text { (0.95 to } 2.43 \text { ) } \\
28-\text { day mortality: similar between } \\
\text { the two groups ( } 22(14 \%] \text { died in the } \\
\text { remdesivir group vs } 10 \text { (13\%) in the } \\
\text { placebo group; difference } 1.1 \% \text { ( } 95 \% \\
\mathrm{Cl}-8.1 \text { to } 10.3) \text { ). }\end{array}$ \\
\hline $\begin{array}{l}\text { WHO Solidarity } \\
\text { Trial } 2020 \\
\text { (randomised } \\
\text { controlled trial) }\end{array}$ & $\begin{array}{l}\text { WHO, Multicentric trial } \\
\text { ( } 405 \text { hospitals in } 30 \\
\text { countries) }\end{array}$ & $\begin{array}{l}\text { Remdesivir (2743); } \\
\text { day } 0,200 \mathrm{mg} \text {; days } \\
1-9,100 \mathrm{mg}\end{array}$ & Placebo (2708) & $\begin{array}{l}\text { Hospitalised with a } \\
\text { diagnosis of } \\
\text { COVID-19, age } \geq 18 \\
\text { years, not known to } \\
\text { have received any study } \\
\text { drug, without anticipated } \\
\text { transfer elsewhere within } \\
72 \text { hours }\end{array}$ & $\begin{array}{l}\text { Mortality rate: } \\
\text { Remdesivir } R R=0.95(0.81 \text { to } 1.11 \text {, } \\
p=0.50 ; 301 / 2743 \text { active vs } 303 / 2708 \\
\text { control). } \\
\text { Hydroxychloroquine } R R=1.19(0.89 \text { to } \\
1.59, p=0.23 ; 104 / 947 \text { vs } 84 / 906) \text {, } \\
\text { Lopinavir } R R=1.00(0.79 \text { to } 1.25, \\
p=0.97 ; 148 / 1399 \text { vs } 146 / 1372) \\
\text { Interferon } R R=1.16(0.96 \text { to } 1.39 \\
p=0.11 ; 243 / 2050 \text { vs } 216 / 2050)\end{array}$ \\
\hline
\end{tabular}

4 RCTs $^{3}{ }^{13-15}$ were included in analysis. One study was excluded as it was single arm study, ${ }^{4}$ one was in Spanish language and other two were non-COVID trial ${ }^{16}$ and historical control study. ${ }^{17}$

\section{Study characteristics}

Study characteristics of RCTs of present systematic review are mentioned in table 1 .

\section{Risk of bias}

The overall ROB was judged as "Low", as ROB for WHO solidarity trial ${ }^{14}$ and Wang $e t a l^{\beta}$ was assessed as low. Study done by Beigel $e t a l^{13}$ and Spinner et $a l^{15}$ was regarded as having "High" ROB. Hence, ROB assessed for outcomes having data only from Beigel et al and Spinner et al in GRADE analysis was regarded as having serious issues.
The ROB of RCTs is represented in figure 2 and online supplemental figure 1 .

\section{Efficacy outcomes \\ Mortality}

Mortality data were included from 4 RCTs with 3818 and 3506 patients in remdesivir and standard of care groups, respectively. Remdesivir was found to have no mortality benefit as compared with control group ( $\mathrm{OR}=0.92(95 \%$ CI 0.79 to 1.07 ), $\mathrm{p}=0.30 ; \mathrm{I}^{2}=0$ ) (figure $3 \mathrm{~A}$ ). Subgroup analysis revealed no mortality benefit in low-risk and high-risk groups (figure 3A, online supplemental figure 2)

\section{Clinical improvement}

Statistically significant increase in rates of clinical improvement in remdesivir versus controls was observed 


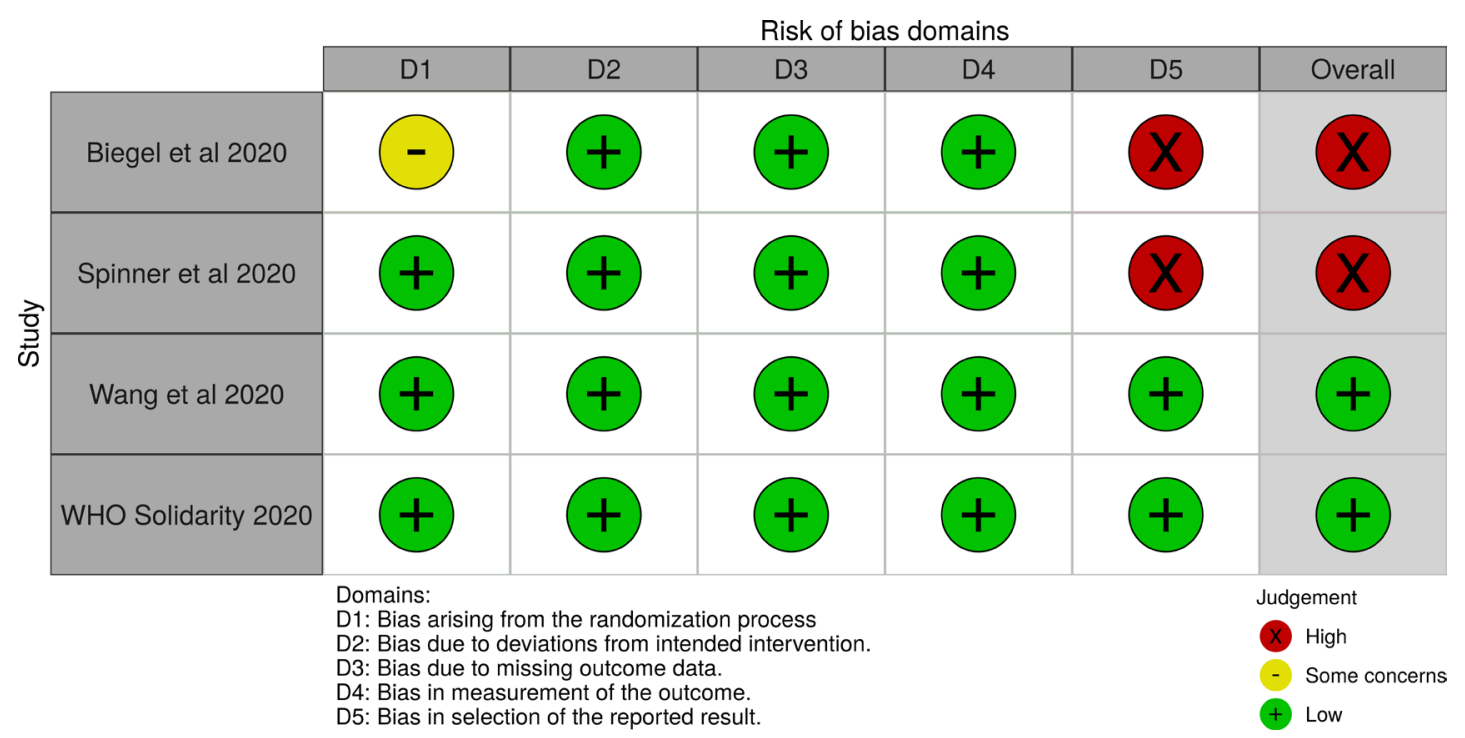

Figure 2 ROB-2: risk of bias in RCT evaluating remdesivir for treatment of COVID-19.

$\left(\mathrm{OR}=1.52 \quad(95 \%\right.$ CI 1.24 to 1.87$\left.), \mathrm{p}<0.0001 ; \mathrm{I}^{2}=0 \%\right)$ (figure 3B). Results were drawn from 3 RCTs with total of 1879 patients.

\section{Time to clinical improvement}

Pooled analysis revealed that there was significantly faster time to clinical improvement in remdesivir group as compared with controls (HR=1.28 (95\% CI 1.12 to 1.46$)$, $\mathrm{p}=0.0002 ; \mathrm{I}^{2}=0 \%$ ) (figure $3 \mathrm{C}$ ). Data extracted from 2 RCTs with total of 1292 patients.

\section{Safety outcomes}

\section{Serious AEs}

Pooled analysis revealed significant decrease in the risk of serious AEs in remdesivir group as compared with control $\left(\mathrm{RR}=0.75 \quad(95 \%\right.$ CI 0.62 to 0.90$\left.), \mathrm{p}=0.0003 ; \mathrm{I}^{2}=0 \%\right)$ (figure 4A). This data were extracted from 3 RCTs with a total of 1875 patients.

\section{Respiratory failure}

No difference in the risk of respiratory failure between remdesivir and control groups was found $(\mathrm{RR}=0.85(95 \%$ CI 0.41 to 1.77 ), $\mathrm{p}=0.67 ; \mathrm{I}^{2}=55 \%$ ) (figure $4 \mathrm{~B}$ ). Findings were derived from 2 RCTs with a total of 1291 patients.

\section{Cost-benefit analysis}

The cost of remdeisvir is US $\$ 2340$ per patient. There is lack of mortality benefit as per our review.

\section{Publication bias}

Though the funnel plot asymmetry was not assessed, the Egger's regression test applied on four studies included in mortality rate assessment showed no publication bias $(\mathrm{t}$ $=-0.5947, \mathrm{p}=0.6123)$.

\section{Grade analysis of the primary and secondary outcomes}

The GRADE analysis recommendation for mortality was 'Moderate' evidence quality. Though there is low ROB, low heterogeneity and direct outcome but there are serious concerns with imprecision. The quality of evidence for clinical improvement and time to clinical improvement were graded as "Low" and "Very Low", respectively. The GRADE recommendation for serious AE and respiratory failure were "Low" and "Very low" quality of evidence respectively, as there was presence of high ROB and high imprecision. The GRADE recommendation is shown in table 2.

\section{DISCUSSION}

With the existing recommendation of USFDA for compassionate use of remdesivir in patients with COVID-19, it is being used worldwide. Current systematic review was planned for formulating recommendation from RCTs evaluating the efficacy of remdesivir in patients with COVID-19.

In the current systematic review, the OR for mortality failed to show any significant mortality benefit with the use of remdesivir. WHO solidarity trial ${ }^{14}$ showed no mortality benefit with the use of remdesivir. Though it was an open-label study, it is less likely to have bias in assessment of objective outcome like mortality. A total of 3451 patients were included in remdesivir and standard of care groups. Subgroup analysis revealed no mortality benefit in low risk (figure $3 \mathrm{~A}-$ no oxygen requirement, online supplemental figure 2, no invasive ventilation) or high risk (figure 3A-oxygen requirement or assisted ventilation, online supplemental figure 2-invasive ventilation) group of patients with remdesivir.

At the time of recruitment, more patients were on invasive mechanical ventilation or extracorporeal membrane oxygenation (ECMO) in the placebo group. There were significantly more AEs reported in the control group in our review. This was due to the high incidence of serious $\mathrm{AE}$ in Beigel et al study. ${ }^{13}$ This is rare occurrence that serious $\mathrm{AE}$ were significantly more in control group. The fact that more severe patients were randomised into control group in the study by Beigel $e a^{13}$ is the major 


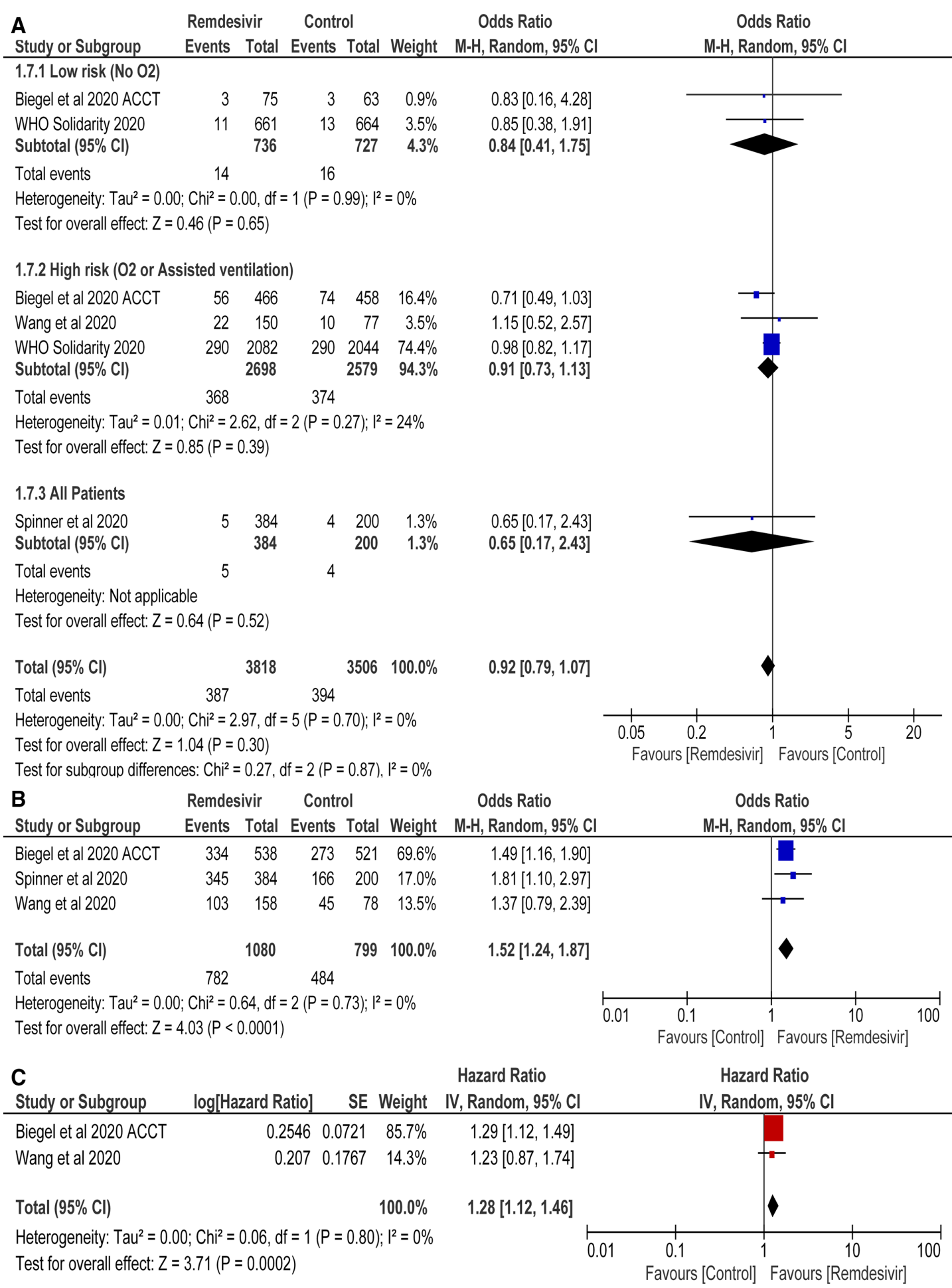

Figure 3 (A) Mortality rate, (B) clinical improvement and (C) time to clinical improvement of remdesivir versus control treatment.

reason for this finding. Similarly, the serious AE which also included the clinical events like renal failure and respiratory failure $(5.2 \%$ in remdesivir and $8 \%$ in placebo arm) were also observed more in placebo group. Despite this imbalance, remdesivir was unable to show superiority in mortality rate.

Subgroup analysis of Beigel $e t a l^{13}$ study revealed that remdesivir resulted in significant rate of clinical improvement in COVID-19 patients on oxygen therapy, while the patients not on oxygen, or on high flow oxygen or noninvasive ventilation and receiving mechanical ventilation or ECMO had similar clinical improvement as standard of care.

Placebo used in Beigel $e t a l^{13}$ study was sulfo-butyl-ether b-cyclodextrin-sodium, used to dissolve remdesivir. The maximum recommended daily dose is approximately $250 \mathrm{mg} / \mathrm{kg}$ solvent used to dissolve remdesivir. ${ }^{13}$ The amount of solvent present in placebo was not quantified 


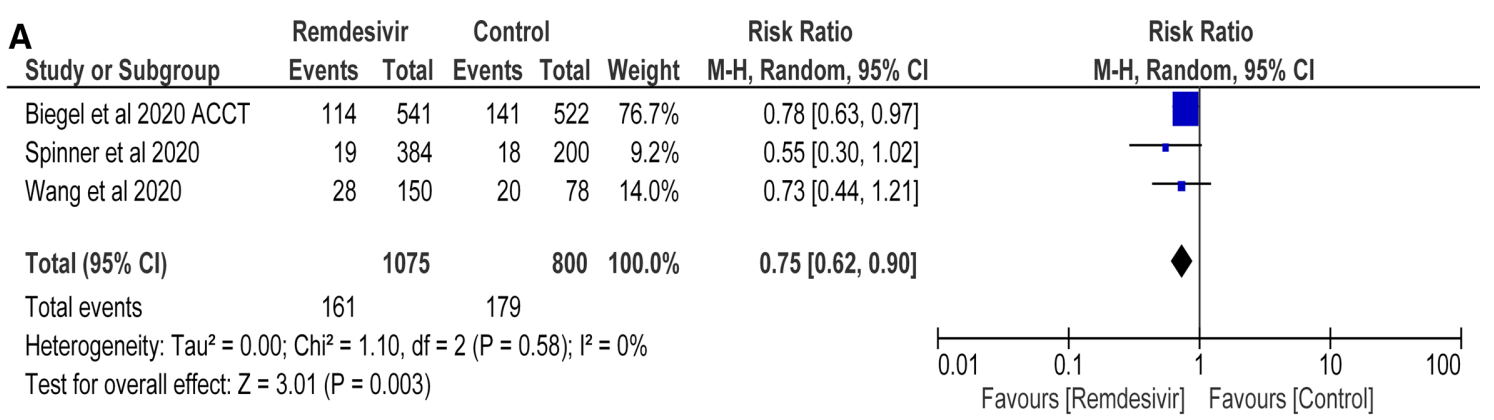

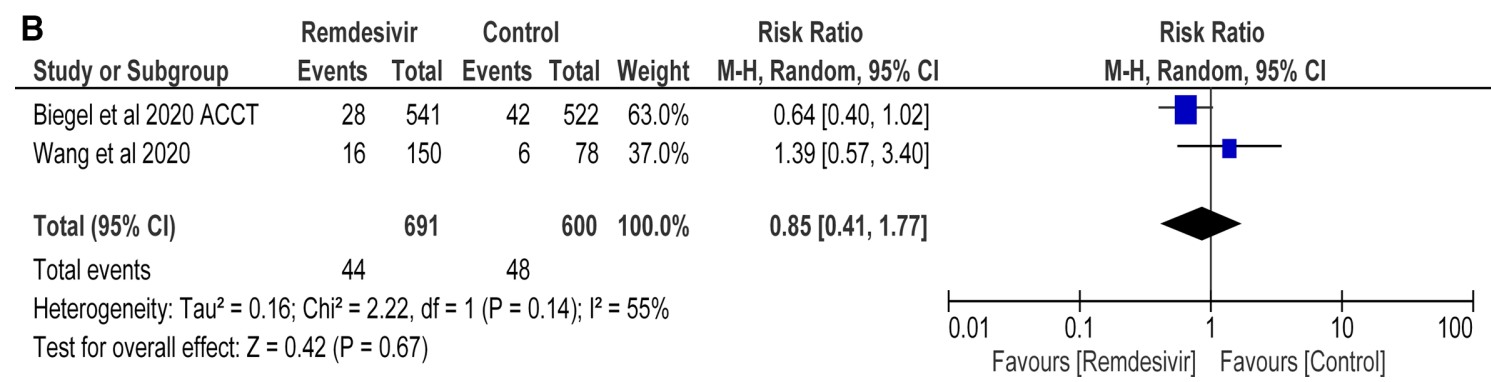

Figure 4 Number of patients with (A) serious adverse events and (B) respiratory failure (remdesivir vs control treatment).

in protocol. Dose of solvent should be modified in patients with eGFR fall of more than $50 \%$ from baseline and is contraindicated in patients with eGFR less than $30 \mathrm{~mL} /$ min. But such modification were not done in either arms. Hence, the effect of solvent on patients with impaired renal function can be detrimental and cannot be ruled out.

In the study by Beigel $e t a l,{ }^{13}$ the median time of administration of drug from randomization was 9 days. Median recovery time from randomization was 11 days. In addition, 302 patients in remdesivir group did not receive 10 days of treatment. Therefore, it is difficult to infer that remdesivir resulted in recovery of patients, as an average of 2 days of administration of remdesivir resulting in complete recovery of patients seems implausible.

Virological cure is also an important outcome which was neglected by the authors. Wang et al reported no difference (percentage difference $=-7.5$ (95\% CI -19.2 to 4.2$)$ ) in undetectable viral RNA load in remdesivir $(75.6 \%)$ and placebo groups $(83.1 \%)$. Patients may become asymptomatic but not cured. It has been observed that asymptomatic patients with RT-PCR positive test can have thromboembolic and chest CT changes. Study done by Merkler et al observed that 8 patients (26\%) out of total 31 patients who had an ischaemic stroke were COVID-19 positive on RT-PCR testing. They did not have any COVID-19 symptoms on presentation. ${ }^{18}$ Silent hypoxaemia is a disturbing feature in asymptomatic patients with COVID-19 and has been found to be associated with poor outcomes. ${ }^{19}$

The Phase 3 SIMPLE trial ${ }^{4}$ results published in New England Journal of Medicine does not include a standard of care group. Similar to Beigel et al virological cure was not reported. ${ }^{4}$ Clinical status at day 14 was similar in 5-day course of remdesivir as compared with 10-day course. However, in comparison to standard care, 5-day group (OR 1.65 (95\% CI 1.09 to 2.48); $\mathrm{p}=0.017$ ) showed significant improvement while 10 day group did not (OR $1.31(95 \%$ CI 0.88 to 1.95$) ; \mathrm{p}=0.18)$. Death reported on day 11 was similar in all three groups. ${ }^{20}$

In another study published by Grein et at in which compassionate use of remdesivir was done, did not have a control arm. Hence, the conclusion that remdesivir is effective cannot be drawn as the possibility of observing similar findings in control arm cannot be ruled out.

Three systematic reviews and meta-analysis were published on remdesivir. ${ }^{21-23}$ However, none of the reviews have included WHO solidarity trials in review. Exclusion of such large study $(n=3451)$ decreases the power of systematic reviews. Our results are different from all three systematic reviews as Wilt et $a l^{23}$ and Shrestha $e t a l^{21}$ have concluded mortality benefit with remdesivir while Elsawah et $a l^{22}$ concluded significant clinical improvement with remdesivir as compared with standard care. Meta-analysis performed by Solidarity trial group $^{14}$ has shown no mortality benefit $(\mathrm{OR}=0.91,95 \% \mathrm{CI}$ 0.79 to 1.05 ), similar to our review. They did not perform meta-analysis with regard to other clinical endpoints and safety outcomes. Also, ROB-2 analysis of included RCTs and GRADE analysis was not applied.

The cost of the drug is US $\$ 2340$ per patient but with no mortality benefit. ${ }^{24}$ According to World Bank data, low and lower middle income countries have Gross National Income per capita less than or equal to $\$ 1035$ and between US $\$ 1036$ to US $\$ 4045$, respectively. ${ }^{25}$ As per WHO Global Health Expenditure database, ${ }^{26}$ current health expenditure per capita in low and lower middle income countries is less than US $\$ 36$ and US\$86, respectively. ${ }^{26}$ Therefore, from a cost-benefit perspective, we are of the opinion that their use should not be recommended, especially in low and lower middle income countries. In case of limited use, strict evidence-based guidelines should be followed for optimum health benefits. The cost of the drug will 


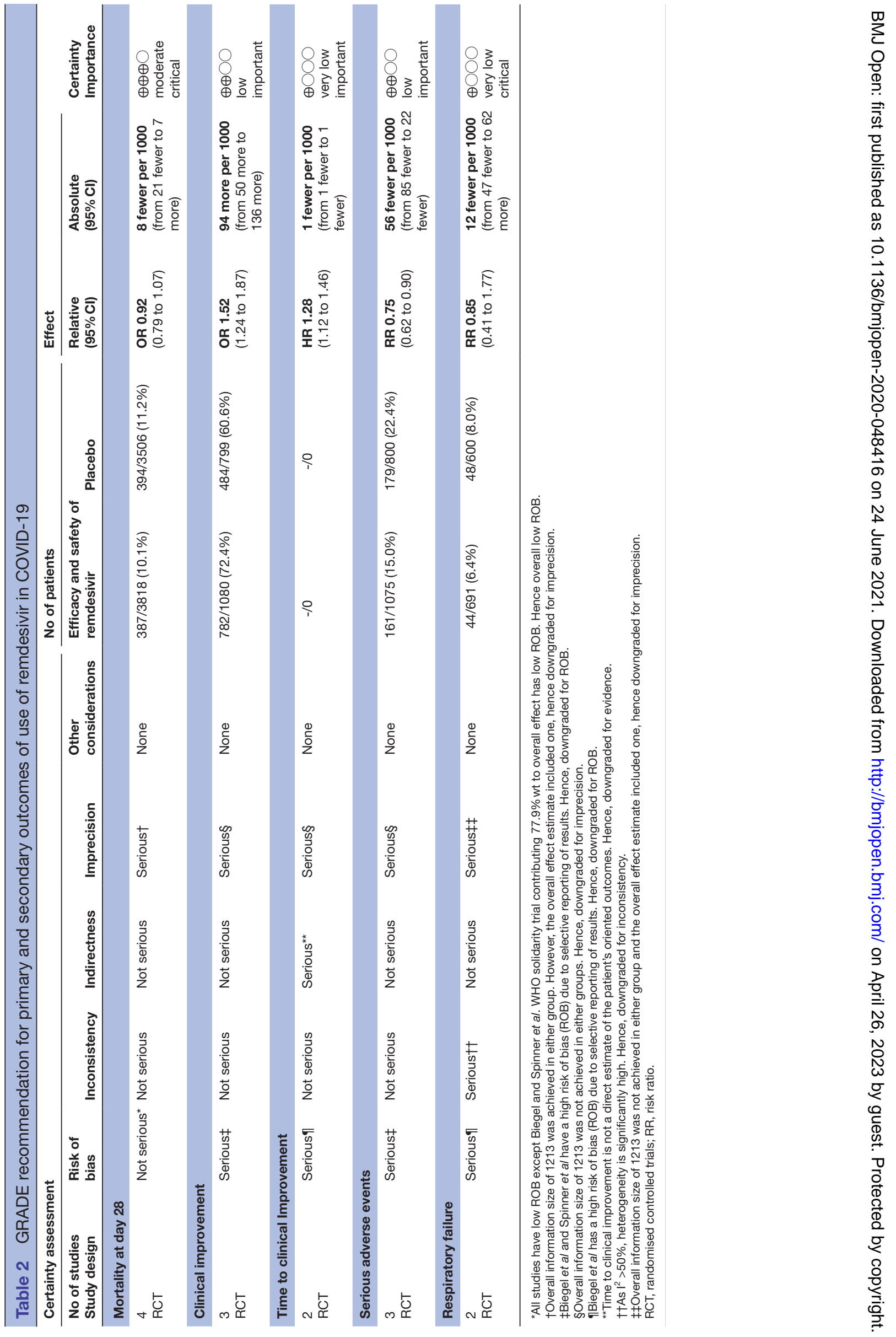


put extra burden on government by increasing the health cost without any benefit. Injudicious use of remdesivir without mortality benefit may also lead to increased incidence of AEs.

\section{Limitations and strengths}

A major strength of our systematic review is that four RCTs were included in our analysis with total sample size of 7324 patients. Study done by Wang et al and WHO Solidarity trial has low ROB. Robust method of analysis using ROB-2 and GRADE analysis is another strength of the current systematic review.

\section{Quality of evidence: (GRADE)}

The overall quality of systematic review is "Moderate". Critical outcomes like mortality has moderate quality evidence. Clinical improvement was regarded as "Low". Time to clinical improvement has "Very low" quality of evidence. Time to clinical improvement was used by regulatory agencies like US FDA for giving approval to remdesivir for treatment of patients with severe COVID19. However, the quality of evidence for time to clinical improvement cannot be overlooked. This evidence suggests that further research is very likely to have an important impact on our confidence in the estimate of time to clinical improvement and likely to change the estimate. Moderate quality of evidence with regard to mortality showed that further RCTs are likely to have important impact and may change the no mortality benefit conclusion drawn from review.

\section{CONCLUSION}

Evidence of our systematic review indicates no benefit in mortality rate with remdesivir, with moderate quality of evidence. Benefit does exist in terms of rates of clinical improvement and faster time to clinical improvement in favour of remdesivir, but the evidence is of low and very low quality, respectively. Significant decrease in serious AEs as compared with placebo strengthens the evidence of more serious patients in placebo arm. No difference was shown in respiratory failure in the two groups (very low quality evidence). All outcomes except mortality in our meta-analysis were influenced by Beigel et al and Spinner et al, which has high ROB. WHO solidarity trial and Wang et al showed no mortality benefit, both having overall low ROB.

Acknowledgements We acknowledge GRADE Pro team [McMaster University and Evidence Prime Inc. available from: https://gradepro.org/] for letting us use the software for the synthesis and overall assessment and grading of systematic review.

Contributors Study design and planning of systematic review: all authors. Literature search: AC, SS, PSK. Figures: SS, VKC, AC. Tables: DK, SS. Data collection and analysis: SS, DK. ROB: DK, AC, SS, query resolved by all authors. GRADE analysis: SS, AC, DK, Query resolved by all authors. Data interpretation: SS, DK, AC. Writing: SS, DK, AC, PSK. Corrections and final approval of manuscript: all of the authors.

Funding The authors have not declared a specific grant for this research from any funding agency in the public, commercial or not-for-profit sectors.
Competing interests None declared.

Patient consent for publication Not required.

Provenance and peer review Not commissioned; externally peer reviewed.

Data availability statement Data are available upon reasonable request. The datasets used and/or analyzed during the current study are available from the corresponding author on request.

Supplemental material This content has been supplied by the author(s). It has not been vetted by BMJ Publishing Group Limited (BMJ) and may not have been peer-reviewed. Any opinions or recommendations discussed are solely those of the author(s) and are not endorsed by BMJ. BMJ disclaims all liability and responsibility arising from any reliance placed on the content. Where the content includes any translated material, BMJ does not warrant the accuracy and reliability of the translations (including but not limited to local regulations, clinical guidelines, terminology, drug names and drug dosages), and is not responsible for any error and/or omissions arising from translation and adaptation or otherwise.

Open access This is an open access article distributed in accordance with the Creative Commons Attribution Non Commercial (CC BY-NC 4.0) license, which permits others to distribute, remix, adapt, build upon this work non-commercially, and license their derivative works on different terms, provided the original work is properly cited, appropriate credit is given, any changes made indicated, and the use is non-commercial. See: http://creativecommons.org/licenses/by-nc/4.0/.

\section{ORCID iD}

Surjit Singh http://orcid.org/0000-0002-8990-3235

\section{REFERENCES}

1 Xu Z, Shi L, Wang Y, et al. Pathological findings of COVID-19 associated with acute respiratory distress syndrome. Lancet Respir Med 2020;8:420-2.

2 Chen N, Zhou M, Dong X, et al. Epidemiological and clinical characteristics of 99 cases of 2019 novel coronavirus pneumonia in Wuhan, China: a descriptive study. Lancet 2020;395:507-13.

3 Wang Y, Zhang D, Du G, et al. Remdesivir in adults with severe COVID-19: a randomised, double-blind, placebo-controlled, multicentre trial. Lancet 2020;395:1569-78.

4 Goldman JD, Lye DCB, Hui DS, et al. Remdesivir for 5 or 10 days in patients with severe Covid-19. N Engl J Med 2020;383:1827-37.

5 Grein J, Ohmagari N, Shin D, et al. Compassionate use of Remdesivir for patients with severe Covid-19. N Engl J Med 2020;382:2327-36.

6 Sterne JA, Hernán MA, Reeves BC, et al. ROBINS-I: a tool for assessing risk of bias in non-randomised studies of interventions. BMJ 2016;355:i4919.

7 McGuinness LA, Higgins JPT. Risk-of-bias visualization (robvis): an R package and shiny web APP for visualizing risk-of-bias assessments. Res Synth Methods 2021;12:55-61.

8 The Cochrane Collaboration.. Review Manager (RevMan) [Computer program]. Version 5.3. Copenhagen: The Nordic Cochrane Centre, 2020.

9 Higgins J, Green S. Cochrane Handbook for systematic reviews of interventions: The Cochrane Collaboration, 2011. Available: www. handbook.cochrane.org

10 Higgins JPT, Thompson SG, Deeks JJ, et al. Measuring inconsistency in meta-analyses. BMJ 2003;327:557-60.

11 Kjaergard LL, Villumsen J, Gluud C. Reported methodologic quality and discrepancies between large and small randomized trials in meta-analyses. Ann Intern Med 2001;135:982-9.

12 Schünemann H, Brożek J, Guyatt G. Grade Handbook for grading quality of evidence and strength of recommendations. Updated October 2013. The grade Working group, 2013. Available: guidelinedevelopment.org/handbook

13 Beigel JH, Tomashek KM, Dodd LE, et al. Remdesivir for the Treatment of Covid-19 - Final Report. N Engl J Med 2020;383:1813-26.

14 WHO Solidarity Trial Consortium, Pan H, Peto R, et al. Repurposed Antiviral Drugs for Covid-19 - Interim WHO Solidarity Trial Results. $N$ Engl J Med 2021;384:497-511.

15 Spinner CD, Gottlieb RL, Criner GJ, et al. Effect of Remdesivir vs standard care on clinical status at 11 days in patients with moderate COVID-19: a randomized clinical trial. JAMA 2020;324:1048-57.

16 Mulangu S, Dodd LE, Davey RT, et al. A randomized, controlled trial of Ebola virus disease therapeutics. $N$ Engl J Med 2019;381:2293-303. 
17 Olender SA, Perez KK, AS G. Remdesivir for severe COVID-19 versus a cohort receiving standard of care. Clinical infectious disease in press;2020.

18 Merkler AE, Parikh NS, Mir S, et al. Risk of ischemic stroke in patients with coronavirus disease 2019 (COVID-19) vs patients with influenza. JAMA Neurol 2020. doi:10.1001/jamaneurol.2020.2730. [Epub ahead of print: 02 Jul 2020].

19 Brouqui P, Amrane S, Million M, et al. Asymptomatic hypoxia in COVID-19 is associated with poor outcome. Int $J$ Infect Dis 2021:102:233-8.

20 Gilead Announces results from phase 3 trial of Remdesivir in patients with moderate COVID-19. Available: https://www.gilead.com/newsand-press/press-room/press-releases/2020/6/gilead-announcesresults-from-phase-3-trial-of-remdesivir-in-patients-with-moderatecovid-19

21 Shrestha DB, Budhathoki P, Syed N-I-H, et al. Remdesivir: a potential game-changer or just a myth? A systematic review and metaanalysis. Life Sci 2021;264:118663.

22 Elsawah HK, Elsokary MA, Abdallah MS. Efficacy and safety of remdesivir in hospitalized Covid-19 patients: systematic review and meta-analysis including network meta-analysis. Rev Med Virol 2020;31:e2187.

23 Wilt TJ, Kaka AS, MacDonald R, et al. Remdesivir for Adults With COVID-19 : A Living Systematic Review for American College of Physicians Practice Points. Ann Intern Med 2021;174:209-20.

24 Rees V. Gilead prices remdesivir at $\$ 2,340$ per patient for developed countries. European Pharmaceutical Review. Available: https://www. europeanpharmaceuticalreview.com/news/122592/gilead-pricesremdesivir-at-2340-per-patient-for-developed-countries/ [Accessed 30 Jun 2020].

25 World Bank, World Development Indicators, World Bank Country and lending groups, 2021. Available: https://datahelpdesk.worldbank.org/ knowledgebase/articles/906519-world-bank-country-and-lendinggroups\#: :text=For\%20the\%20current\%202021\%20fiscal,those\% 20with\%20a\%20GNI\%20per

26 World Bank, World Development Indicators. World Health Organization Global Health Expenditure database (apps.who.int/nha/ database), 2018. Available: https://data.worldbank.org/indicator/SH. XPD.CHEX.PC.CD?locations=XM 